\title{
Body iron and lead status in early childhood and its effects on development and cognition: a longitudinal study from urban Vellore
}

\author{
Beena Koshy ${ }^{1, *} \odot$, Manikandan Srinivasan ${ }^{2}$, Susan Mary Zachariah ${ }^{1}$, \\ Arun S Karthikeyan ${ }^{2}$, Reeba Roshan ${ }^{1}$, Anuradha Bose ${ }^{3}$, Venkata Raghava Mohan ${ }^{3}$, \\ Sushil John ${ }^{4}$, Karthikeyan Ramanujam², Jayaprakash Muliyil ${ }^{2}$ and Gagandeep Kang ${ }^{2}$ \\ 'Developmental Paediatrics Unit, Christian Medical College, Vellore, Tamil Nadu 632004, India: ${ }^{2}$ Wellcome \\ Research Unit, Christian Medical College, Vellore, Tamil Nadu 632004, India: ${ }^{3}$ Community Health, Christian Medical \\ College, Vellore, Tamil Nadu 632004, India: ${ }^{4}$ Low Cost Effective Care Unit, Christian Medical College, Vellore, Tamil \\ Nadu 632004, India
}

Submitted 8 October 2018: Final revision received 25 0ctober 2019: Accepted 29 October 2019: First published online 14 April 2020

\begin{abstract}
Objective: Early childhood factors can have persisting effects on development and cognition in children. We propose to explore the trends of Fe deficiency and $\mathrm{Pb}$ toxicity in early childhood and their association with child development at 2 years of age and cognition at 5 years.

Design: Longitudinal birth cohort study.

Setting: Urban slum, Vellore, India.

Participants: Children enrolled at birth were followed up regularly in the first 2 years with developmental and cognitive assessments at 2 and 5 years of age, respectively.

Results: The birth cohort enrolled 251 children with 228 children followed up at 2 years and 212 at 5 years of age. Fe deficiency (ID) was highest at 15 months of age and improved subsequently at 24 months. Blood Pb levels (BLL) remained high at all age groups with an increasing trend with age; $97 \%$ at 36 months having high BLL. Persistent high mean BLL at 15 and 24 months had negative association with both cognition and expressive language raw scores of 24 months, while high mean BLL at 15, 24 and 36 months had no significant association with any of the domains of cognition at 5 years of age. Early childhood cumulative body Fe status at 7, 15 and 24 months did not show any association with child development at 2 years, but was associated with verbal, performance and processing speed components of cognition at 5 years.

Conclusions: Optimising body $\mathrm{Fe}$ status and limiting $\mathrm{Pb}$ exposure in early childhood can augment child development and school entry cognition.
\end{abstract}

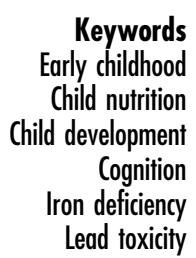

It is now recognised that the 'first 1000 days of life', from conception to the second birthday, are critical for brain development. This has resulted in an extensive exploration of early childhood factors to understand their potential impact on child development and sequentially human potential $^{(1)}$. There are many genetic, environmental and epigenetic factors that affect child's development, and it is challenging to identify a single factor, the deficiency of which is common, easy to detect and treat, and amenable for community-level interventions.
Micronutrient deficiencies such as that of Fe and I, especially in early infancy, can have long-term effects on cognition and behaviour, probably due to their impact on the rapidly developing brain during the 'first 1000 days of life $e^{(2,3)}$. Fe deficiency (ID) is considered as the most common nutritional deficiency among all age groups and is prevalent across all social strata ${ }^{(2,4)}$. Fe is vital, not just for the synthesis of $\mathrm{Hb}$ but also for the non-haematological effects on mitochondrial and neuroendocrine function ${ }^{(4)}$. ID therefore affects cognition and behaviour in children, 
and these changes can be long term. Although there are studies evaluating anaemia and Fe status and their effects on cognition, there is a dearth of evidence, of the long-term effect of ID in early childhood, especially from low-middle income countries.

In addition to micronutrient deficiency, $\mathrm{Pb}$ exposure in early childhood can adversely affect child development including cognition. Even low levels of $\mathrm{Pb}$ exposure during the early childhood brain development stage can have lasting effects on cognition and behaviour ${ }^{(5)}$. With increasing recognition of the adverse effects of high $\mathrm{Pb}$ levels on young brains, there has been a revision of the cut-off for elevated blood $\mathrm{Pb}$ levels (BLL) from $0.48 \mu \mathrm{mol} / \mathrm{l}(10 \mu \mathrm{g} / \mathrm{dl}$ ) to $0.24 \mu \mathrm{mol} / 1(5 \mu \mathrm{g} / \mathrm{dl})$ by the American Academy of Pediatrics ${ }^{(6,7)}$. Background deficiency of micronutrients particularly that of Fe can modify the impact of exposure to high levels of $\mathrm{Pb}$ through pica and competitive inhibition of intestinal absorption ${ }^{(8,9)}$. A previous study from the same birth cohort had reported high BLL at 15 and 24 months of age in children ${ }^{(10)}$. The objective of the current study was to evaluate the trends of both $\mathrm{Fe}$ and $\mathrm{Pb}$ status in early childhood and the association of cumulative early childhood $\mathrm{Fe}$ and $\mathrm{Pb}$ status on development at 2 years of age and cognition at 5 years of age.

\section{Materials and methods}

\section{Study population and metbodology}

The study population was a birth cohort followed up for the Etiology, Risk Factors and Interactions of Enteric Infections and Malnutrition and the Consequences for Child Health and Development (MAL-ED) Network, a multinational, longitudinal prospective cohort study conducted in eight countries across the world ${ }^{(11)}$. The study site in India was eight adjacent urban slum dwelling areas, located in Old Town, Salavanpet and neighbouring areas in Vellore, South India, with a population density of $42000 / \mathrm{km}^{2(12)}$, compared with 6200/ $\mathrm{km}^{2}$ in Rio de Janeiro and $32000 / \mathrm{km}^{2}$ in Harlem, NYC. A population of 12000 was covered for the current study. All pregnant women in the study site were identified by door-to-door survey and invited to participate in the study immediately after the delivery, by consecutive sampling. The enumeration process carried out prior to recruitment provided the probable number of births in the study area based on recent births and the number of pregnant mothers. Using this information, it was planned to recruit more than 200 children over the 2-year period, the target number for each site as per the MAL-ED study protocol (for details, refer to John et $\left.a l^{(12)}\right)$. Mothers were screened based on the following exclusion criteria - having pre-existing plans for migration during the study period, having another child from the same family being enrolled in the MAL-ED study, multiple pregnancies, having a neonate with medical complications and unavailability of mothers to provide informed consent.
Babies of mothers who consented were enrolled, and their demographic characteristics along with anthropometry measurements were recorded. Babies were enrolled at a mean (range) age of 10.08 (0-16) d. Trained fieldworkers visited their home twice a week for active disease surveillance for the first 2 years of life. The initial birth cohort recruitment was conducted between March 2010 and February 2012 and recruited 251 children, and baseline demographic data of the birth cohort were comparable to that of the study area ${ }^{(12)}$. The cohort was further followed up at 36 and 60 months of age.

Blood samples were collected at 7, 15, 24, 36 and 60 months. Samples were tested for $\mathrm{Hb}$ (at 7, 15, 24, 36 and 60 months); Fe and ferritin assays (at 7, 15 and 24 months) and for BLL (at 15, 24 and 36 months). All children underwent a developmental assessment at 7, 15, 24 and 36 months of age using Bayley Scales of Infant and Toddler Development-3rd edition (BSID-III) and cognitive assessment at 5 years of age, using Wechsler Preschool Primary Scales of Intelligence - third edition (WPPSI-III). Child development is defined as the ability of the child in domains of motor, language, cognition, play, social and adaptive skills ${ }^{(13)}$. Cognition or intelligence is defined as a combination of multiple abilities in a child ${ }^{(14)}$. The original study and further follow-up studies were approved by the institutional review board. The current study was conducted according to the guidelines laid down in the Declaration of Helsinki, and all procedures involving human subjects namely growth monitoring, cognition assessments and blood collection were approved by the institutional review board, Christian Medical College, Vellore, India. Written informed consent was obtained from the parents/caregivers of all the subjects.

\section{Study measures}

\section{Blood collection}

Venous blood was collected from children to a maximum quantity of $5 \mathrm{ml}$ at each visit. $\mathrm{Hb}$ was analysed using a point-of-care screening tool, Hemocue ${ }^{\circledR} \mathrm{Hb} 301$ kit (azide-methemoglobin method), at the study clinic immediately after blood collection using a drop of blood. One millilitre of the collected venous blood was used for BLL analysis and preserved with K2 EDTA, and the remaining blood was stored in the biochemistry tube for analysis of serum ferritin and transferrin levels. The samples were refrigerated and transported using cold packs to the research laboratory within $2 \mathrm{~h}$ of blood collection for further analysis. Serum ferritin, transferrin receptors and $\mathrm{Pb}$ levels were tested in the Biochemistry department, Christian Medical College, Vellore. Chemiluminescence immunoassay was done for serum ferritin analysis using Siemens Advia Centaur (Model Siemens Advia Centaur $\mathrm{Xp}$ Chemiluminescence immune assay) with $0.5 \mu \mathrm{g}$ $(11.24 \mathrm{pmol})$ as limit of detection. For estimating 
transferrin levels, Immunoturbidimetry was performed using Roche Coba C system (model Roche Cobas C 702 Immunoturbidimetry assay) with $10 \mu \mathrm{g}(0.13 \mu \mathrm{mol})$ as limit of detection. Using the Graphite Furnace Atomic Absorption Spectroscopy method in M-series Atomic Absorption Spectro-photometer (model Thermo Scientific $\mathrm{X}$ series 2.ICP-MS), BLL were estimated with $0.5 \mu \mathrm{g}$ $(0.024 \mu \mathrm{mol})$ as limit of detection.

\section{Bayley Scales of Infant and Toddler Development-III}

The BSID-III assesses development in the domains of gross motor, fine motor, expressive language, receptive language and cognition between 1 and 42 months of age ${ }^{(13)}$. The measure was culturally adapted, translated and piloted prior to administration. A single trained psychologist conducted the testing in a standardised child friendly setting in the community clinic for each age group. Around $5-6 \%$ of the tests were video-recorded and centrally reviewed for quality control purposes ${ }^{(15)}$. For the purpose of current analysis, the 24-month assessment was used, as 2 years denote the completion of infancy and the '1000-day window' period ${ }^{(1)}$. Receptive and expressive language and cognition domain raw scores were derived for each child from the 24-month assessment. Receptive and expressive language skills measure receptive and expressive abilities of children in primary language and communication areas, while cognition measures sensorimotor development, exploration and manipulation, object relatedness, concept formation and memory ${ }^{(13)}$.

\section{Wechsler Preschool and Primary Scales of Intelligence-third edition}

The WPPSI-III can be administered to children aged between 2 years 6 months and 7 years 3 months and assesses cognition in the domains of verbal, performance and processing speed. This measure was adapted centrally for cultural appropriateness and was translated and piloted in local settings before being administered by a single trained psychologist. Verbal, performance and processing speed raw scores were obtained after administration for each child. Ten percentage of these assessments were recorded and reviewed centrally for quality control.

Maternal intelligence was assessed at 6-8 months of child age by Raven's progressive matrices ${ }^{(16)}$. This time of assessment was chosen in the protocol for mothers' convenience as they would be able to leave their babies with another caregiver around this time, to complete cognitive assessment in the study clinic. To assess the socio-economic status (SES), a socio-economic index was created using Water and sanitation, Assets, Maternal education and household Income (WAMI) and SES of the families was assessed at recruitment and six-monthly intervals as per the study protocol ${ }^{(17)}$. The WAMI index was validated against prevalence of stunting in all the eight countries involved in the MAL-ED cohort study ${ }^{(17)}$. The broader aim of the main study was to assess the predictors of early child development, amongst which SES influences child development through both biological and physical home environment ${ }^{(11,18)}$.

As serum ferritin levels can be influenced by inflammation, total body Fe levels were calculated from ferritin (F) and transferrin (R) levels as below ${ }^{(19)}$ :

$$
\text { Body iron }\left(\frac{\mathrm{mg}}{\mathrm{kg}}\right)=\left(\frac{-\left(\log \left(\frac{R}{F} \text { ratio }\right)-2 \cdot 8229\right)}{0 \cdot 1207}\right)
$$

Positive values indicated Fe surplus in stores, while negative values indicated deficiency of Fe in tissues.

\section{Data entry and analysis}

The Data Coordinating Center developed a double data entry database application. Forms were checked for completeness and accuracy of the data by data supervisors before being entered into the application. Discrepancies between the first and second entry were cleared by data supervisors after rechecking forms, and this process of cross validation was done for quality control of the study. The data was analysed using STATA 13 (StataCorp). Missing data values were limited as this was a prospective study with rigorous quality checks. If a child did not have information at one time point, that child was excluded from corresponding analysis and no missing value corrections were applied.

Mean and SD were used to summarise $\mathrm{Hb}, \mathrm{Pb}$, ferritin and transferrin levels measured at each time point. A birth weight $<2.5 \mathrm{~kg}$ was considered as low birth weight category. We reported children who were anaemic $(\mathrm{Hb}<11 \mathrm{~g} / \mathrm{dl})^{(20)}$, Fe deficient (blood $\mathrm{Fe}<0 \mathrm{mg} / \mathrm{kg}$ ) and with elevated BLL $(>0.24 \mu \mathrm{mol} / \mathrm{l})$ using proportions. Characteristics of the study children such as sex and SES at 2 nd and 5 th year of follow-up were compared with baseline data using 'Chi-square for trends'. Mean values of $\mathrm{Hb}$ across the time points (7, 15, 24, 36 and 60 months) were compared using repeated-measures ANOVA. Bonferroni test was used for post hoc analysis, to compare the $\mathrm{Hb}$ levels between any of the two time points measured. Estimates of median serum ferritin, transferrin and BLL across each time point were compared using Friedman's test, and post hoc analysis between any of the two points was done using Wilcoxon Signed-rank test. Proportions of children with anaemia, ID and elevated $\mathrm{Pb}$ levels across each time point were compared using 'Chi-square for trends'. The proportion with ID in anaemic children was evaluated to understand causes of anaemia in each age group setting. The outcome variables namely child development (BSID-III) measured at 2 years were expressed as raw scores of cognition, expressive language and receptive language domains, and cognition (WPPSI-III) measured at 5 years was expressed as raw 
scores of verbal, performance and processing speed domains. Median (IQR - interquartile range) was used to summarise the scores under each domain of the outcome variables. Cronbach's alpha was used to assess the internal consistency within items under each domain of outcome measures to evaluate if the responses provided by the subject remained consistent. Since $\mathrm{Fe}$ and $\mathrm{Pb}$ levels were analysed at different time points, a summary statistic approach was used and the repeatedly measured information was condensed to a single number per subject ${ }^{(21,22)}$. Mean body Fe was derived by averaging the body Fe levels at 7, 15 and 24 months, and this measure was considered for analysis at both 2 and 5 years. Mean BLL was derived by averaging the BLL at 15 and 24 months for analysis at 2 years, and those at 15, 24 and 36 months for analysis at 5 years.

Linear regression modelling was done to find the predictors of the outcome variables - BSID-III and WPPSI-III scores using separate models. The predictors that were included in the model were - sex of the child, maternal intelligence raw scores, SES, mean body Fe levels and mean BLL. In the bivariate analysis, unadjusted beta coefficient along with $95 \%$ CI was reported for each predictor. A multivariable linear regression was performed using the same set of predictors listed above. Following assumptions of linear regression were tested - normality of the outcome variable using Shapiro-Wilk test and multicollinearity of predictors using correlation matrix were tested. Only those independent variables with the correlation coefficient ( $r$ value) of $<0.5$ in the multicollinearity analysis were retained in the model. The standardised beta coefficient along with $95 \%$ CI of the predictor variables was noted. In the post-estimation analysis, homoscedasticity of the residuals was assessed using Breusch-Pagan test. The level of significance for the test of association was considered at $P<0.05$.

\section{Results}

After visiting 301 pregnant mothers, 251 children were enrolled at birth after parental consent, as ten mothers refused to participate and forty mothers did not fulfil the screening criteria (screen failures). Reasons for screen failures included pre-existing plans for migration during the study period ( $n 5$ ), another child of the same family being part of the MAL-ED study ( $n 8)$, multiple pregnancy $(n 1)$, presence of pre-existing morbidities in children $(n 7)$ and mothers not available to give informed consent $(n 9)$ and a combination of two or more of the above reasons ( $n$ 10). On follow-up, 228 children participated at 2 years of age and 212 children at 5 years of age (Fig. 1) and there

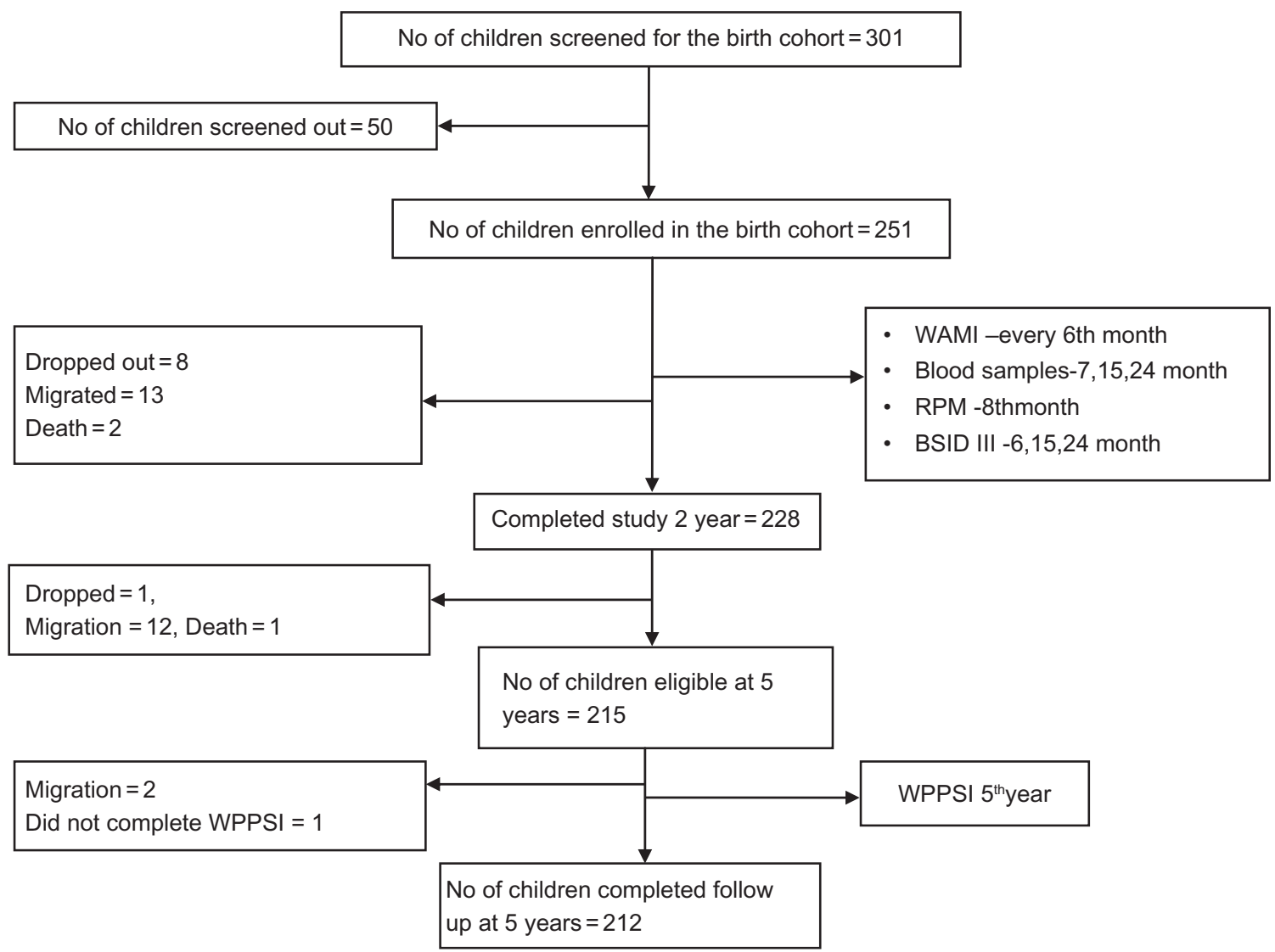

Fig. 1 Flow chart depicting the follow-up of the birth cohort. WAMI, Water and sanitation, Assets, Maternal education and Income score for socio-economic status; RPM, Raven's progressive matrices; BSID III, Bayley Scales of Infant and Toddler Development III; WPPSI III, Wechsler Preschool Primary Scales of Intelligence 
Table 1 Characteristics of study children at enrolment, 2 and 5 years of age

\begin{tabular}{|c|c|c|c|c|}
\hline Characteristics & $\begin{array}{c}\text { Enrolment } \\
(N 251)\end{array}$ & $\begin{array}{c}\text { At } \\
2 \text { years } \\
(N 228)\end{array}$ & $\begin{array}{c}\text { At } \\
5 \text { years } \\
(N 212)\end{array}$ & $P^{\star}$ \\
\hline \multicolumn{5}{|l|}{ Sex } \\
\hline \multicolumn{5}{|l|}{ Male } \\
\hline$n$ & 113 & 105 & 98 & 0.960 \\
\hline$\%$ & $45 \cdot 0$ & $46 \cdot 0$ & $46 \cdot 2$ & \\
\hline \multicolumn{5}{|l|}{ Female } \\
\hline$n$ & 138 & 123 & 114 & \\
\hline$\%$ & $55 \cdot 0$ & $54 \cdot 0$ & 53.8 & \\
\hline \multicolumn{5}{|l|}{ SES (WAMI) } \\
\hline \multicolumn{5}{|l|}{ Low } \\
\hline$n$ & $71 \dagger$ & 71 & 65 & 0.955 \\
\hline $\begin{array}{l}<33 \text { rd } \\
\text { centile }\end{array}$ & $30 \cdot 2$ & $31 \cdot 1$ & $30 \cdot 7$ & \\
\hline \multicolumn{5}{|l|}{ High } \\
\hline$n$ & $164 \dagger$ & 157 & 147 & \\
\hline $\begin{array}{l}\geq 33 \text { rd } \\
\text { centile }\end{array}$ & $69 \cdot 8$ & 68.9 & $69 \cdot 3$ & \\
\hline \multicolumn{5}{|c|}{ Maternal IQ - raw score } \\
\hline Median & & $46 \cdot 5$ & 45 & - \\
\hline Range & & $8-68$ & $8-68$ & - \\
\hline
\end{tabular}

SES, socio-economic status; WAMI, Water and sanitation, Assets, Maternal education and Income score; IQ, intelligence quotient.

*Using $\chi^{2}$ for trends.

†Baseline SES data were available only for 235 children.

was no significant difference in the socio-demographic characteristics between participants at baseline and at 2 or 5 years of age follow-ups (Table 1 ). Loss to followup was mainly due to migration of the families (Fig. 1)

The birth cohort had a mean (range) family size of 5.7 (3-13) and the mean (range) educational year of the head of the family was $6 \cdot 8(0-18)^{(12)}$. The mean BMI of mothers was $22(\mathrm{SD} 3.9) \mathrm{kg} / \mathrm{m}^{2}$ with 20.3 and $21.1 \%$ of mothers being underweight and overweight/obese, respectively. The cohort participants were predominantly girls (56\%), and the mean birth weight was 2.8 (SD 0.44) $\mathrm{kg}$. Seventeen percentage of babies were low birth weight and weighed $<2.5 \mathrm{~kg}$ at birth. The mean exclusive breast-feeding duration was 76.9 (SD 43.8) $\mathrm{d}$.

There was a reduction in $\mathrm{Hb}$ levels between 7 and 15 months; however, this reduction was not significant $(P=1.000)$ (Table 2$)$. Subsequently, there was a significant increase in the $\mathrm{Hb}$ levels at 15, 24 and 36 months (15 v. 24 months, $P=0.012 ; 24 v .36$ months, $P=0 \cdot 0001)$. Although ferritin levels significantly dropped between 7 and 24 months $(P<0.0001)$, there was no change at 36 months (15 $v$. 36 months, $P=0.3745$ ). There was a significant increase in mean BLL across the three time points (15 v. 24 months, $P<0.0001 ; 24 v$. 36 months, $P=0.0001$ ) (Table 2 ).

More than half of the children were anaemic at 7 and 15 months of age, with subsequent improvements in $\mathrm{Hb}$ levels at 24, 36 and 60 months. Almost half of the study group ( $46 \cdot 1 \%$ ) had low Fe status at 15 months of age (Table 3). Across the time points, there was an increase in proportion of anaemia attributable to ID from 19\% at 7 months to $68 \%$ at 24 months (Fig. 2).

The Cronbach's alpha for internal consistency was $0.927,0.712$ and 0.727 for expressive language, receptive language and cognition domains of BSID-III at 2 years of age, respectively, and $0.789,0.705$ and 0.802 for verbal, performance and processing speed domains of WPPSI-III

Table 2 Trend of $\mathrm{Hb}$, ferritin, transferrin and lead levels at different time points of the cohort follow-up

\begin{tabular}{|c|c|c|c|c|c|c|c|c|c|c|c|c|c|c|c|c|}
\hline \multirow[b]{2}{*}{ Indicator } & \multicolumn{3}{|c|}{7 months } & \multicolumn{3}{|c|}{15 months } & \multicolumn{3}{|c|}{24 months } & \multicolumn{3}{|c|}{36 months } & \multicolumn{3}{|c|}{60 months } & \multirow[b]{2}{*}{$P$} \\
\hline & $N$ & Mean & SD & $N$ & Mean & SD & $N$ & Mean & SD & $N$ & Mean & SD & $N$ & Mean & SD & \\
\hline $\mathrm{Hb}(\mathrm{gm} / \mathrm{dl})$ & 233 & $10 \cdot 8$ & $1 \cdot 2$ & 228 & $10 \cdot 6$ & $1 \cdot 3$ & 225 & $10 \cdot 9$ & 1.4 & 112 & 11.5 & $1 \cdot 2$ & 159 & $11 \cdot 8$ & 0.9 & $<0.0001$ \\
\hline Ferritin (pmol/l) & 230 & $91 \cdot 2$ & 123.4 & 221 & 33.9 & $45 \cdot 6$ & 222 & $41 \cdot 6$ & $60 \cdot 4$ & NA & NA & & NA & NA & & $<0.0001$ \\
\hline Transferrin $(\mu \mathrm{mol} / \mathrm{l})$ & 218 & $16 \cdot 8$ & $11 \cdot 2$ & 226 & $27 \cdot 1$ & 20.7 & 225 & $27 \cdot 6$ & 20.7 & NA & NA & & NA & NA & & 0.001 \\
\hline $\mathrm{Pb}(\mu \mathrm{mol} / \mathrm{l})$ & NA & NA & & 228 & 0.5 & 0.3 & 223 & 0.6 & 0.4 & 113 & 0.6 & 0.3 & NA & NA & & 0.002 \\
\hline
\end{tabular}

$N$, total number of children whose blood samples were available for analysis at respective time points; NA, not available.

Table 3 Percentage of children with anaemia $(\mathrm{Hb}<11 \mathrm{gm} / \mathrm{dl})$, low body iron stores and high blood lead level $(>0.24 \mu \mathrm{mol} / \mathrm{l})$

\begin{tabular}{|c|c|c|c|c|c|c|c|c|c|c|c|}
\hline \multirow{2}{*}{$\begin{array}{l}\text { Indicator } \\
\mathrm{Hb} \text { status }\end{array}$} & \multicolumn{2}{|c|}{7 months } & \multicolumn{2}{|c|}{15 months } & \multicolumn{2}{|c|}{24 months } & \multicolumn{2}{|c|}{36 months } & \multicolumn{2}{|c|}{60 months } & \multirow[b]{2}{*}{$P$} \\
\hline & $N$ & $\%$ & $N$ & $\%$ & $N$ & $\%$ & $N$ & $\%$ & $N$ & $\%$ & \\
\hline Children with anaemia & 120 & $51 \cdot 5$ & 129 & $56 \cdot 6$ & 96 & $42 \cdot 7$ & 35 & $31 \cdot 3$ & 24 & $15 \cdot 1$ & $<0.0001$ \\
\hline Children without anaemia & 113 & 48.5 & 99 & 43.4 & 129 & $57 \cdot 3$ & 77 & 68.7 & 135 & 84.9 & \\
\hline \multicolumn{12}{|l|}{ Body Fe status } \\
\hline Children with Fe deficiency & 24 & $11 \cdot 1$ & 102 & $46 \cdot 1$ & 96 & $42 \cdot 9$ & NA & & NA & & $<0.0001$ \\
\hline Children without Fe deficiency & 192 & 88.9 & 119 & $53 \cdot 9$ & 128 & $57 \cdot 1$ & NA & & NA & & \\
\hline \multicolumn{12}{|l|}{ Blood level status } \\
\hline Children with elevated blood Pb level & NA & & 228 & 89.9 & 214 & 95.9 & 110 & $97 \cdot 3$ & NA & & 0.004 \\
\hline Children without elevated blood $\mathrm{Pb}$ level & NA & & 23 & $10 \cdot 1$ & 9 & $4 \cdot 1$ & 3 & $2 \cdot 7$ & NA & & \\
\hline
\end{tabular}

$N$, the total number of children whose blood samples were available for analysis at respective time points; NA, not available. 


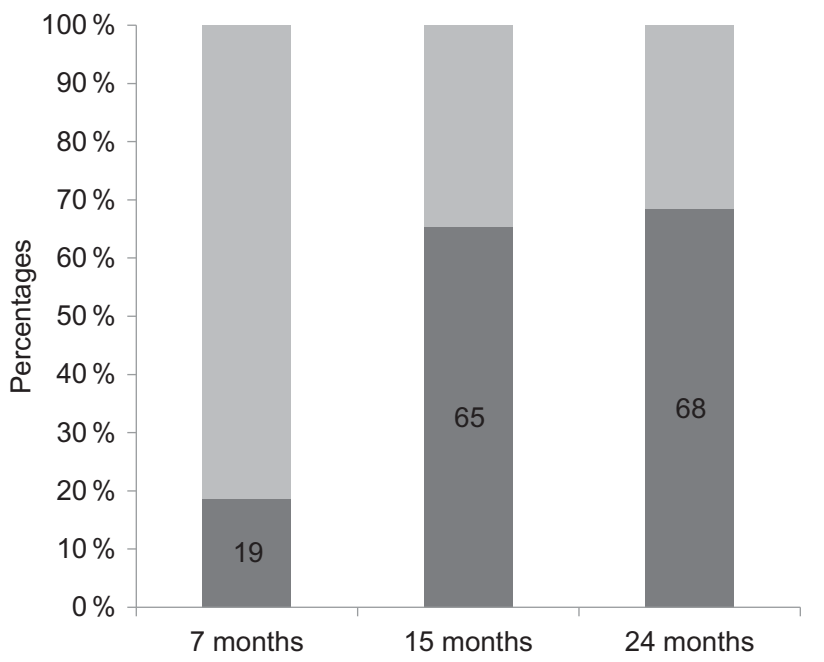

Fig. 2 Proportion of iron deficiency in anaemic children at 7, 15 and 24 months of age. -, Anaemia due to caused other than iron deficiency; $\square$, iron deficiency anaemia

Table 4 Outcome raw scores of development and cognition using Bayley Scales of Infant and Toddler Development III (BSID III) and Wechsler Preschool Primary Scales of Intelligence IV (WPPSI IV) measured at 2 and 5 years, respectively

\begin{tabular}{lrrrr}
\hline & Mean & SD & Median & IQR \\
\hline Development scores at 2 years $\left(N 227^{\star}\right)$ & & & \\
Cognition & 59.5 & 3.4 & 59 & $57-62$ \\
Expressive language & 27.8 & 4.7 & 29 & $25-31$ \\
Receptive language & 26.9 & 2.5 & 27 & $25-29$ \\
Cognition scores at 5 years $(N 212)$ & & & & \\
Verbal & 37.9 & 9.2 & 39 & $32-44$ \\
Performance & 48.2 & 9.8 & 48 & $42-54$ \\
Processing speed & 35.8 & 18.4 & 35 & $22-50$
\end{tabular}

$I Q R$, interquartile range.

* Of the 228 children who completed 2 years of follow-up, one subject did not have complete developmental raw scores. at 5 years of age, respectively. Median raw scores for expressive language, receptive language and cognition were 27 (IQR 16-33), 29 (IQR 15-36) and 59 (IQR 47-69), respectively, at 2 years of age, while the median raw scores at 5 years of age for verbal, performance and processing speed domains were 39 (IQR 13-69), 48 (IQR 22-75) and 35 (IQR 1-86), respectively (Table 4).

The multivariate models built for each domain of the child development measured at 2 years of age (Table 5) were statistically significant $(P<0.01)$ and had an adjusted $R^{2}$ value ranging between 5 and $7 \%$ (adjusted $R^{2}$ values of cognition, expressive language and receptive language domains were $4.6,7.2$ and $4.7 \%$, respectively). Considering the collinearity between the body $\mathrm{Fe}$ and $\mathrm{Hb}$ (correlation coefficient, $r=0.63$ ), the $\mathrm{Hb}$ was excluded from the final model. High mean BLL of 15 and 24 months was associated with lower cognition and expressive language raw scores at 2 years of age, which remained significant in the multivariate analysis with sex, mean body Fe (of 7, 15 and 24 months), maternal intelligence and SES (Table 5). Mean body Fe did not have any association with either cognition, expressive or receptive language scores at 2 years of age. Other factors associated with the 2 year development in the multivariate analysis were the SES associated with both cognition and expressive language; girls had better expressive language than boys, and higher maternal intelligence was associated with better receptive language.

Linear models constructed for each domain of cognition assessed at 5 years of age (Table 6 ) were statistically significant $(P<0.0001)$ and had an adjusted $R^{2}$ value ranging between 10 and $13 \%$ (adjusted $R^{2}$ values of verbal, performance and processing speed domains were 9.8, 12.3 and $12.7 \%$, respectively). Body Fe status of early childhood

Table 5 Factors associated with cognition, expressive and receptive language components of Bayley Scales of Infant and Toddler Development III (BSID III) raw scores assessed at 2 years $\left(N 226^{*}\right)$

\begin{tabular}{|c|c|c|c|c|c|c|}
\hline & $\begin{array}{l}\text { Unadjusted beta } \\
\text { coefficient }\end{array}$ & $95 \% \mathrm{Cl}$ & $P \dagger$ & $\begin{array}{l}\text { Adjusted beta } \\
\text { coefficient }\end{array}$ & $95 \% \mathrm{Cl}$ & $P+$ \\
\hline \multicolumn{7}{|l|}{ Cognition } \\
\hline Sex & $-0 \cdot 1$ & $-0.9,0.9$ & 0.977 & -0.3 & $-1 \cdot 2,0 \cdot 6$ & 0.529 \\
\hline Mean body Fe $\ddagger$ & 0.1 & $-0.1,0.2$ & 0.131 & 0.1 & $-0.1,0.2$ & 0.306 \\
\hline Mean blood Pb§ & $-0 \cdot 1$ & $-0.2,-0.02$ & 0.009 & $-0 \cdot 2$ & $-0.2,-0.03$ & 0.009 \\
\hline Mother's IQ scores & 0.1 & $-0.01,0.06$ & 0.203 & 0.01 & $-0.03,0.05$ & 0.712 \\
\hline WAMI & 1.5 & $0.5,2.4$ & 0.002 & 1.4 & $0.4,2.4$ & 0.006 \\
\hline \multicolumn{7}{|l|}{ Expressive language } \\
\hline Sex & 1.7 & $0.5,2.3$ & 0.006 & 1.4 & $0.2,2 \cdot 7$ & 0.020 \\
\hline Mean body Feł & $0 \cdot 1$ & $-0.02,0.3$ & 0.111 & 0.04 & $-0.1-0.2$ & 0.548 \\
\hline Mean blood Pb§ & -0.2 & $-0.3,-0.06$ & 0.003 & -0.2 & $-0.3,-0.1$ & 0.006 \\
\hline Mother's IQ scores & 0.04 & $-0.02,0.09$ & 0.64 & 0.1 & $-0.5,0.07$ & 0.673 \\
\hline WAMI & 1.6 & $0.3,2 \cdot 9$ & 0.015 & 1.5 & $0.09,2 \cdot 8$ & 0.036 \\
\hline \multicolumn{7}{|l|}{ Receptive language } \\
\hline Sex & 0.4 & $-0.2,1 \cdot 1$ & 0.188 & 0.2 & $-0.4,0.9$ & 0.473 \\
\hline Mean body Feł & 0.07 & $-0.02,0.2$ & 0.125 & 0.03 & $0.05,0.1$ & 0.408 \\
\hline Mean blood $\mathrm{Pb \S}$ & -0.04 & $-0.1,0.02$ & 0.185 & -0.04 & $-0.1,0.02$ & 0.205 \\
\hline Mother's IQ scores & 0.05 & $0.02,0.08$ & 0.001 & 0.04 & $0.01,0.07$ & 0.007 \\
\hline WAMI & 0.8 & $0.6,1.5$ & 0.034 & 0.4 & $-0 \cdot 3,1 \cdot 1$ & 0.294 \\
\hline
\end{tabular}

$I Q$, intelligence quotient; WAMI, Water and sanitation, Assets, Maternal education and Income score for socio-economic status.

*Of the 228 children who completed 2 years of follow-up, two subjects had missing data either in blood Pb levels or in development scores; hence, the linear model includes data for only 226 children.

†Significant associations in unadjusted and adjusted analyses are presented in bold letters.

¥Mean cumulative body $\mathrm{Fe}$ of 7,15 and 24 months.

$\S$ Mean cumulative blood $\mathrm{Pb}$ levels of 15 and 24 months. 
Table 6 Factors associated with verbal, performance and processing speed components of Wechsler Preschool Primary Scales of Intelligence IV (WPPSI IV) raw scores assessed at 5 years (N212)

\begin{tabular}{|c|c|c|c|c|c|c|}
\hline & $\begin{array}{l}\text { Unadjusted beta } \\
\text { coefficient }\end{array}$ & $95 \% \mathrm{Cl}$ & $P^{\star}$ & $\begin{array}{l}\text { Adjusted beta } \\
\text { coefficient }\end{array}$ & $95 \% \mathrm{Cl}$ & $P^{\star}$ \\
\hline \multicolumn{7}{|l|}{ Verbal } \\
\hline Sex & $1 \cdot 1$ & $-1.4,3 \cdot 6$ & 0.379 & -0.1 & $-2 \cdot 5,2 \cdot 4$ & 0.978 \\
\hline Mean body Fe† & 0.5 & $0.2,0.9$ & 0.001 & 0.4 & $0.1,0.7$ & 0.011 \\
\hline Mean blood Pb $\ddagger$ & -0.1 & $-0.3,0.1$ & 0.423 & -0.1 & $-0.3,0.1$ & 0.462 \\
\hline Mother's IQ scores & 0.3 & $0.1,0.4$ & $<0.0001$ & 0.2 & $0.1,0.3$ & $<0.0001$ \\
\hline WAMI category & $3 \cdot 1$ & $0 \cdot 4,5 \cdot 7$ & 0.025 & 0.9 & $-1 \cdot 9,3.6$ & 0.524 \\
\hline \multicolumn{7}{|l|}{ Performance } \\
\hline Sex & -0.3 & $-2 \cdot 9,2 \cdot 3$ & 0.813 & $-1 \cdot 73$ & $-4 \cdot 2,0 \cdot 8$ & 0.182 \\
\hline Mean blood Fe† & 0.6 & $0.3,0.96$ & $<0.0001$ & 0.5 & $0.2,0.8$ & 0.003 \\
\hline Mean blood Pb‡ & -0.2 & $-0.5,0.02$ & 0.071 & -0.2 & $-0.5,-0.1$ & 0.056 \\
\hline Mother's IQ scores & 0.2 & $0.1,0.3$ & $<0.0001$ & 0.2 & $0.04,0.3$ & 0.009 \\
\hline WAMI category & 4.9 & $2 \cdot 1,7 \cdot 8$ & $<0.0001$ & $3 \cdot 1$ & $0.2,5.9$ & 0.037 \\
\hline \multicolumn{7}{|l|}{ Processing speed } \\
\hline Sex & $6 \cdot 5$ & $1.6,11.4$ & 0.010 & 4.3 & $-0 \cdot 4,9 \cdot 1$ & 0.076 \\
\hline Mean body Fe† & 1.3 & $0.6,1.9$ & $<0.0001$ & 0.9 & $0.2,1.5$ & 0.007 \\
\hline Mean blood Pbł & $-0 \cdot 16$ & $-0.7,0.4$ & 0.493 & -0.1 & $-0.5,0.3$ & 0.682 \\
\hline Mother's IQ scores & 0.5 & $0.2,0.7$ & $<0.0001$ & 0.3 & $0.1,0.6$ & 0.005 \\
\hline WAMI category & $8 \cdot 7$ & $3 \cdot 3,13.9$ & 0.002 & $4 \cdot 7$ & $-0 \cdot 7,10$ & 0.090 \\
\hline
\end{tabular}

IQ, intelligence quotient; WAMI, Water and sanitation, Assets, Maternal education and Income score for socio-economic status. *Significant associations in unadjusted and adjusted analyses are presented in bold letters. †Mean cumulative body $\mathrm{Fe}$ of 7,15 and 24 months. ¥Mean cumulative $\mathrm{Pb}$ levels of 15,24 and 36 months.

(cumulative values of 7,15 and 24 months) had a significant association with verbal, performance and processing speed at 5 years of age, which remained significant in the multivariate analysis (Table 6). Mean BLL did not have a significant association with any of the domains of cognition assessed at 5 years of age. Other factors associated with the 5 year cognition in the multivariate analysis were the maternal intelligence affecting verbal, performance and processing speed components and SES the performance domain.

\section{Discussion}

This prospective birth cohort follow-up study from urban Vellore provided the trends of $\mathrm{Hb}, \mathrm{Fe}$ and $\mathrm{Pb}$ levels during the early childhood. Further, a negative association of high BLL with cognition and expressive language domains of child development was demonstrated. The current study also showed a negative association of ID with verbal, performance and processing domains of cognition. Retention in the current study was good at all planned time points. There was minimal drop out and 212 children presented at 5 years of age (Table 1). Our finding of high prevalence of anaemia in more than half of the study children at both 7 and 15 months of age has been reported from other studies and reviews ${ }^{(23-26)}$. The proportion of anaemia attributable to ID was only $18.7 \%$ at 7 months. ID anaemia became the commonest cause of anaemia at 15 months of age and remained so at 24 months, despite a drop in overall prevalence of anaemia and improvement in Fe stores in the later age group. Prevalence of anaemia in
Indian children aged 6-59 months was estimated to be 58.5 and $69.4 \%$ in National Family Health Survey (NFHS) conducted during 2015-2016 (NFHS-4) and 2005-2006 (NFHS-3), respectively. Although the prevalence of anaemia had lowered to $58.5 \%$ in NFHS-4, from its previous estimate of $69.4 \%$ in NFHS-3, anaemia continues to be a public health problem in India ${ }^{(27)}$. Other studies from India also had reported that anaemia was common in the older age group with a prevalence ranging between 27 and $63 \%{ }^{(28,29)}$. Other causes of anaemia in children from low-middle income countries are hookworm infestation with resultant blood loss, vitamin $\mathrm{B}_{12}$ deficiency manifesting as megaloblastic anaemia, haemoglobinopathy disorders and environmental enteropathy ${ }^{(23,30,31)}$. However, the association between above-mentioned causes of anaemia and cognitive development was not investigated in the current analysis.

Young children showed the lowest body Fe status at 15 months of age probably due to a combination of factors such as increased Fe demand to support the expanding blood volume requirements, depletion of antenatal $\mathrm{Fe}$ stores and sub-optimal $\mathrm{Fe}$ intake ${ }^{(23)}$.The estimated daily requirement of absorbed $\mathrm{Fe}$ in the first year of life ranges between 0.55 and $0.75 \mathrm{mg}$ and cannot be fully met by breast milk, which has a mean Fe level of $0.4 \mathrm{mg} / \mathrm{l}^{(32)}$. Typical weaning foods used in South India are rice- and milk-based and contain low Fe. Introduction of animal source foods, which can be a good source of dietary Fe, into a child's diet is usually later in this community, unlike other communities where meat is added earlier on ${ }^{(26)}$. This might explain the lowest body Fe status shown at 15 months of age and is corroborated with other 
low-middle income countries studies ${ }^{(32,33)}$. Fe status improved in the second year in this study, probably due to the child eating more variety of food from the family pot with a decrease in consumption of milk and milk products $^{(26)}$.

Most of the Fe in our body is bound in haem proteins and storage proteins, and around $3 \%$ is bound with critical enzyme systems such as cytochromes and peroxidases. ID manifesting during the early childhood, when there is biologically an increased demand for Fe, can be detrimental especially to critical Fe-dependent enzymes ${ }^{(34)}$. It is possible therefore that ID can cause deficiencies in mitochondrial function, neurotransmitter synthesis and neuronal maturation in the brain, which can have long-lasting effects on cognition ${ }^{(4,35-37)}$.

High BLL as in the current study have been reported from India ${ }^{(38-40)}$. Previous studies had used BLL of $10 \mu \mathrm{g} / \mathrm{dl}(0.48 \mu \mathrm{mol} / \mathrm{l})$ as the cut-off for high level; but the revised cut-off of $5 \mu \mathrm{g} / \mathrm{dl}(0.24 \mu \mathrm{mol} / \mathrm{l})$ has been used for the current analysis ${ }^{(6,7,41)}$. This current communitybased prospective study shows increasing $\mathrm{Pb}$ levels from 15 to 36 months of age, with high $\mathrm{Pb}$ levels present in $97 \%$ of children $(>5 \mu \mathrm{g} / \mathrm{dl}(0 \cdot 24 \mu \mathrm{mol} / \mathrm{l}))$ at 36 months of age. This has been reported also from Nepal, in a hospital-based study of 6-36 months old children, where $64.4 \%$ had high BLL of $>5 \mu \mathrm{g} / \mathrm{dl}(0.24 \mu \mathrm{mol} / \mathrm{l})^{(42)}$. Risk factors associated with high BLL include low SES, industrial area exposure, playing with dirt and mud, exposure to enamel paints, piped water supply and mud/clay floors of the house; the last two factors being shown as predictors for high BLL in this birth cohort in an evaluation published earlier ${ }^{(10,38-44)}$. There is evidence suggesting transplacental transfer of $\mathrm{Pb}$, with sixteen (84.2\%) cord blood samples obtained from nineteen mothers, who had high BLL during their antenatal period, had elevated $\mathrm{Pb}$ levels ${ }^{(45)}$. This highlights the possibility of $\mathrm{Pb}$ exposure even as early as the in utero phase of life. In the current study, the continued environmental exposure to $\mathrm{Pb}$ during early childhood could have caused increasing BLL trends.

There can be interactions between $\mathrm{Pb}$ and $\mathrm{Fe}$. ID can cause pica, which can exaggerate $\mathrm{Pb}$ exposure through mouthing of inanimate objects ${ }^{(8,9)}$. Heavy metals including $\mathrm{Pb}$ share intestinal Fe absorption pathways, where there can be competitive inhibition between $\mathrm{Pb}$ and $\mathrm{Fe}^{(8)}$. The classic clinical manifestation of $\mathrm{Pb}$ poisoning in children is anaemia, more specifically hypochromic microcytic anaemia $^{(41)}$. The prevalence and severity of anaemia correlate directly with BLL. Younger and Fe-deficient children are at higher risk of developing $\mathrm{Pb}$-induced anaemia. $\mathrm{Pb}$ toxicity results in anaemia through two mechanisms - by causing direct damage to the cell membrane of erythrocytes resulting in haemolysis and through inhibition of the enzyme delta-aminolevulinic acid dehydratase in the Fe-dependent haem synthesis pathway ${ }^{(41,46)}$. Inhibition of delta-aminolevulinic acid dehydratase enzyme not only results in anaemia by affecting haem synthesis but also results in the accumulation of haem precursors such as aminolevulinic acid, which can cause harmful effects to the nervous system ${ }^{(46,47)}$.

In the current study, high mean BLL over 15 and 24 months had negative association with both cognition and expressive language raw scores of 24 months. Literature shows that early childhood $\mathrm{Pb}$ exposure can adversely affect later age cognitive capability - a doubling of BLL or tooth $\mathrm{Pb}$ levels at 2 years of age can cause a mean deficit of 1-2 intelligence quotient points at 5 years of age ${ }^{(48,49)} \cdot \mathrm{Pb}$ even in smaller dose exposure is toxic to the nervous system and can impair cognition and behaviour; thus the recommendation that there is no safe $\mathrm{BLL}^{(6,41)}$. Pb interferes with ion channels in the brain by its function as a $\mathrm{Ca}$ analogue ${ }^{(6,46)}$. In addition, $\mathrm{Pb}$ increases oxidative stress by generation of reactive oxygen species and inactivates antioxidants such as glutathione by binding to them ${ }^{(50,51)}$. Pb can accumulate over time as shown in the current study and can have a negative association with cognition and learning such as impaired visual-motor integration, longer reaction time and reading disability in school age years; which persist into young adulthood ${ }^{(40,49)}$.

The finding of the current study is that early childhood cumulative body Fe status had no association with development at 2 years of age, but was associated with verbal, performance and processing speed components of cognition at 5 years. This may be due to the fact that cognition is a stable construct at 5 years as frontal lobes are better myelinated and mature at this age ${ }^{(1,52)}$. Early onset ID through its impact on the activity of Fe containing enzymes can affect neuronal myelination, mitochondrial function and neurotransmitter metabolism of developing brain, which can have long-term effects on cognition and behaviour of children $^{(3,4,34,53)}$. Subsequent Fe supplementation beyond the early childhood can optimise body Fe stores, but cannot neutralise the impact of early onset ID on neurodevelopment, cognition and behaviour ${ }^{(2,53,54)}$. ID in school age years can also affect cognition, as per other Indian studies $^{(24,28,30,55)}$. Among cognitive functions, ID impairs executive function the most, which includes but not limited to attention, inhibitory control, planning ability and working memory ${ }^{(3,4,36,54)}$. ID can also cause concentration and attention problems, tiredness and low mood in school-age years; which can improve on appropriate $\mathrm{Fe}$ supplementation $^{(3,54)}$. ID without anaemia in women of reproductive age group was shown to affect their executive function, indicating the need to evaluate ID on its own without the ramification of presence or absence of anaemia ${ }^{(56)}$. Antenatal or early childhood Fe supplementation shows inconsistent effects on both early- and long-term cognition in children ${ }^{(37,57,58)}$.

Other factors that have association with development and cognition in the current study are maternal cognition, SES factors and sex. Maternal intelligence can 
affect child cognition not just by genetic influence ${ }^{(59)}$ but also by providing optimal macro- and micro-environments including appropriate play materials and stimulating experiences ${ }^{(15,60,61)}$. Improvement in SES factors such as access to safe water and sanitation, better maternal education status and improvement of family economy can offer better experiences for children to grow and develop ${ }^{(17)}$. Repeated diarrhoeal illnesses predisposed by lack of safe water and sanitation facilities in the early childhood can have direct negative impact on child development and cognition. Indirect impact of diarrhoeal illnesses on cognition is through manifestation of nutritional deficiencies following these illnesses, which in turn affects cognitive development. In addition to these infections, exposure of toxins such as $\mathrm{Pb}$ can further affect the cognition ${ }^{(15,61)}$. Girls tend to have better speech and expressive language skills than boys at 2 years of age, as shown in the current analysis, probably due to better environmental interactions ${ }^{(62,63)}$.

The current study has strengths such as longitudinal birth cohort follow-up, standardised developmental and cognitive assessments by a single trained psychologist, rigorous quality control with internal and external reviews, standardised laboratory assessments and adjustment for SES. However, regression models could explain only up to $13 \%$ of the variance associated with the predicted outcomes, highlighting the presence of other factors that could have influenced the outcome. A comparatively smaller sample size prevented a detailed analysis of other factors within the model. Inclusion of factors such as years of preschool education could have made the model more explanatory. Due to the collinearity between serum Fe and $\mathrm{Hb}$ levels, the latter was not included in the regression; which can also be a limitation to the current study. Despite these limitations, this prospective birth cohort study showed that high BLL in early childhood was negatively associated with development at 2 years of age and the association of early childhood ID with cognition at the age of 5 years. Future studies can explore the contribution of other early childhood micronutrient deficiency and environmental toxicity to development and cognition, and the ideal timing of nutritional interventions such as Fe supplementation and fortification.

\section{Significance}

This longitudinal birth cohort shows maximum ID at 15 months of age and increasing BLL with age in a lowmiddle income country setting.

Early childhood ID shows a negative association with verbal, performance and processing speed domains of cognition at 5 years of age, while high BLL was negatively associated with cognition and expressive language at 2 years of age.

\section{Acknowledgements}

Acknowledgements: The authors thank the participants, their families and staff of the MAL-ED Network project. Financial support: The Etiology, Risk Factors and Interactions of Enteric Infections and Malnutrition and the Consequence for Child Health and Development Project (MAL-ED) is carried out as a collaborative project supported by the Bill and Melinda Gates Foundation, the Foundation for the NIH and the National Institutes of Health/Fogarty International Center. Conflict of interest: None. Authorship: Drs G.K., S.J., A.B., J.M., V.R.M., R.R. and B.K. are involved in the birth cohort study planning, recruitment and follow-up as well as in the planning, analysis, write-up and correction of the current study. Drs M.S., S.M.Z. and A.S.K. are involved in the 5 year study planning, recruitment, data analysis, write-up and corrections. Mr K.R. is data coordinator, who entered and analysed data and is involved in the study write-up and corrections. All authors approved the final manuscript. Ethics of buman subject participation: This study was conducted according to the guidelines laid down in the Declaration of Helsinki and all procedures involving human subjects/patients were approved by the Institutional Review Board, Christian Medical College, Vellore. Written informed consent was obtained from all participants' parents.

\section{References}

1. Biesalski HK (2016) The 1,000-day window and cognitive development. World Rev Nutr Diet 115, 1-15.

2. Yehuda S, Rabinovitz S, Mostofsky DI (2006) Nutritional deficiencies in learning and cognition. J Pediatr Gastroenterol Nutr 43, Suppl. 3, S22-S25.

3. Benton D (2008) Micronutrient status, cognition and behavioral problems in childhood. Eur J Nutr 47, 38-50.

4. Jáuregui-Lobera I (2014) Iron deficiency and cognitive functions. Neuropsychiatr Dis Treat 10, 2087-2095.

5. World Health Organization (2018) Lead Poisoning and Health. Geneva: WHO.

6. American Academy of Pediatrics Council on Environmental Health (2016) Prevention of childhood lead toxicity. Pediatrics 138e, $1-15$.

7. American Academy of Pediatrics Committee on Environmental Health (2005) Lead exposure in children: prevention, detection, and management. Pediatrics 116, 1036-1046.

8. Hegazy AA, Zaher MM, Abd El-Hafez MA et al. (2010) Relation between anemia and blood levels of lead, copper, zinc and iron among children. BMC Res Notes $\mathbf{3}, 133$.

9. Wigg NR (2001) Low-level lead exposure and children. J Paediatr Child Health 37, 423-425.

10. Mohan VR, Sharma S, Ramanujam K et al. (2014) Effects of elevated blood lead levels in preschool children in urban Vellore. Indian Pediatr 51, 621-625.

11. MAL-ED Network Investigators (2014) The MAL-ED study: a multinational and multidisciplinary approach to understand the relationship between enteric pathogens, malnutrition, gut physiology, physical growth, cognitive development, and immune responses in infants and children up to 2 years 
of age in resource-poor environments. Clin Infect Dis $\mathbf{5 9}$ Suppl. 4, S193-S206.

12. John SM, Thomas RJ, Kaki S et al. (2014) Establishment of the MAL-ED birth cohort study site in Vellore, Southern India. Clin Infect Dis 59, Suppl. 4, S295-S299.

13. Bayley N (2005) Bayley Scales of Infant and Toddler Development III. San Antonio, TX: Psychological Corp.

14. Gardner H (1993) The Theory of Multiple Intelligence (10th Anniversary Edition), 10th ed. New York: Basic Books.

15. Murray-Kolb LE, Rasmussen ZA, Scharf RJ et al. (2014) The MAL-ED cohort study: methods and lessons learned when assessing early child development and caregiving mediators in infants and young children in 8 low- and middle-income countries. Clin Infect Dis 59, S261-S272.

16. Raven J, Raven JC \& Court JH (2003) Manual for Raven's Progressive Matrices and Vocabulary Scales. San Antonio, TX: Harcourt Assessment.

17. Psaki SR, Seidman JC, Miller M et al. (2014) Measuring socioeconomic status in multicountry studies: results from the eight-country MAL-ED study. Popul Health Metr 12, 8.

18. Mal-Ed Network Investigators (2017) Childhood stunting in relation to the pre- and postnatal environment during the first 2 years of life: the MAL-ED longitudinal birth cohort study. PLoS Med 14, e1002408.

19. Cook JD, Flowers CH \& Skikne BS (2003) The quantitative assessment of body iron. Blood 101, 3359-3364.

20. World Health Organization (2011). Haemoglobin Concentrations for the Diagnosis of Anaemia and Assessment of Severity. Geneva: WHO. https://www.who.int/vmnis/ indicators/haemoglobin.pdf.

21. Schober P \& Vetter TR (2018) Repeated measures designs and analysis of longitudinal data: if at first you do not succeed - try, try again. Anesth Analg 127, 569-575.

22. Senn S, Stevens L \& Chaturvedi N (2000) Repeated measures in clinical trials: simple strategies for analysis using summary measures. Stat Med 19, 861-877.

23. Kotecha PV (2011) Nutritional anemia in young children with focus on Asia and India. Indian J Community Med 36, 8-16.

24. Subramaniam G \& Girish M (2015) Iron deficiency anemia in children. Indian J Pediatr 82, 558-564.

25. Dos Santos RF, Gonzalez ES, de Albuquerque EC et al. (2011) Prevalence of anemia in under five-year-old children in a children's hospital in Recife, Brazil. Rev Bras Hematol Hemoter 33, 100-104.

26. Reinbott A, Jordan I, Herrmann J et al. (2016) Role of breastfeeding and complementary food on hemoglobin and ferritin levels in a cambodian cross-sectional sample of children aged 3 to 24 months. PLOS ONE 11, e0150750.

27. Ministry of Health and Family Welfare (2016) National Family Health Survey 4: NFHS 4. Mumbai: International Institute for Population Studies.

28. Thalanjeri P, Karanth H, Shankar VMS et al. (2016) Impact of iron deficiency anemia on cognition of school children of South India. Indian J Clin Anat Physiol 3, 135-138.

29. More S, Shivkumar VB, Gangane N et al. (2013) Effects of iron deficiency on cognitive function in school going adolescent females in rural area of Central India. Anemia 2013, 5.

30. Batra J, Sood A (2005) Iron deficiency anaemia: effect on congnitive development in children: a review. Indian J Clin Biochem 20, 119-125.

31. Darnton-Hill I \& Mkparu UC (2015) Micronutrients in pregnancy in low- and middle-income countries. Nutrients 7, 1744-1768.

32. Joo EY, Kim KY, Kim DH et al. (2016) Iron deficiency anemia in infants and toddlers. Blood Res 51, 268-273.

33. Meinzen-Derr JK, Guerrero ML, Altaye M et al. (2006) Risk of infant anemia is associated with exclusive breast-feeding and maternal anemia in a Mexican Cohort. $J$ Nutr 136, 452-458.
34. Brittenham GM (2005) Disorders of iron metabolism: Iron deficiency and overload. In Hematology Basic Principles and Practice, 4th ed, pp. 481 [R Hoffman, EJ Benz Jr, SJ Shattil, editors]. New York: Churchill Livingstone.

35. van der Merwe LF \& Eussen SR (2017) Iron status of young children in Europe. Am J Clin Nutr 106, 1663s-1671s.

36. Wenger MJ \& DellaValle DM (2017) Effect of iron deficiency on simultaneous measures of behavior, brain activity, and energy expenditure in the performance of a cognitive task. Nutr Neurosci 7, 1-10.

37. Larson LM, Phiri KS \& Pasricha SR (2017) Iron and cognitive development: what is the evidence? Ann Nutr Metab $\mathbf{7 1}$, Suppl. 3, 25-38.

38. Kalra V, Chitralekha KT, Dua T et al. (2003) Blood lead levels and risk factors for lead toxicity in children from schools and an urban slum in Delhi. J Trop Pediatr 49, 121-123.

39. Kalra V, Sahu JK, Bedi P et al. (2013) Blood lead levels among school children after phasing-out of leaded petrol in Delhi, India. Indian J Pediatr 80, 636-640.

40. Palaniappan K, Roy A, Balakrishnan K et al. (2011) Lead exposure and visual-motor abilities in children from Chennai, India. Neurotoxicology 32, 465-470.

41. World Health Organization (2010) Childhood Lead Poisoning. Geneva: WHO. https://www.who.int/news-room/fact-sheets/ detail/lead-poisoning-and-health.

42. Dhimal M, Karki KB, Aryal KK et al. (2017) High blood levels of lead in children aged 6-36 months in Kathmandu Valley, Nepal: a cross-sectional study of associated factors. PLOS ONE 12, e 0179233 .

43. Roy A, Hu H, Bellinger DC et al. (2009) Predictors of blood lead in children in Chennai, India (2005-2006). Int J Occup Environ Health 15, 351-359.

44. Chaudhary S, Firdaus U, Ali SM et al. (2018) Factors associated with elevated blood lead levels in children. Indian Pediatr 55, 38-40.

45. Sindhu KN, Bondu JD, Ganesan SK et al. (2018) Blood lead levels in mother-infant pairs. Ind J Ped 85, 1143-1144.

46. Wani AL, Ara A \& Usmani JA (2015) Lead toxicity: a review. Interdiscip Toxicol 8, 55-64.

47. Bandeen-Roche K, Glass TA, Bolla KI et al. (2009) Cumulative lead dose and cognitive function in older adults. Epidemiology 20, 831-839.

48. Pocock SJ, Smith M \& Baghurst P (1994) Environmental lead and children's intelligence: a systematic review of the epidemiological evidence. BMJ 309, 1189-1197.

49. Needleman HL, Schell A, Bellinger D et al. (1990) The longterm effects of exposure to low doses of lead in childhood. An 11-year follow-up report. $N$ Engl J Med 322, 83-88.

50. Lopes AC, Peixe TS, Mesas AE et al. (2016) Lead exposure and oxidative stress: a systematic review. Rev Environ Contam Toxicol 236, 193-238.

51. Mah V \& Jalilehvand F (2012) Lead(II) complex formation with glutathione. Inorg Chem 51, 6285-6298.

52. Lenroot RK \& Giedd JN (2006) Brain development in children and adolescents: insights from anatomical magnetic resonance imaging. Neurosci Biobehav Rev 30, 718-729.

53. Dallman PR (1993) Iron deficiency anemia: a synthesis of current scientific knowledge and U.S. recommendations for prevention and treatment. In Iron Deficiency Anemia: Recommended Guidelines for the Prevention, Detection, and Management Among US Children and Women of Childbearing Age, pp. 1-124 [Institute of Medicine, editor]. Washington, DC: The National Academies Press.

54. Beard JL \& Connor JR (2003) Iron status and neural functioning. Ann Rev Nutr 23, 31-58.

55. Chauhan U, Golhar S \& Dahake P (2016) Correlation between iron deficiency anemia and cognitive achievement in school aged children. Ann Int Med Den Res $\mathbf{2}$, $178-180$ 
56. Scott SP \& Murray-Kolb LE (2016) Iron status is associated with performance on executive functioning tasks in nonanemic young women. J Nutr 146, 30-37.

57. Guo XM, Liu H \& Qian J (2015) Daily iron supplementation on cognitive performance in primary-school-aged children with and without anemia: a meta-analysis. Int J Clin Exp Med 8, 16107-16111.

58. Hermoso M, Vucic V, Vollhardt C et al. (2011) The effect of iron on cognitive development and function in infants, children and adolescents: a systematic review. Ann Nutr Metab 59, 154-165.

59. Gecz J \& Mulley J (2000) Genes for cognitive function: developments on the X. Genome Res 10, 157-163.
60. Giustardi A, Stablum M \& De Martino A (2011) Mother infant relationship and bonding myths and facts. J Matern Fetal Neonatal Med 24, 59-60.

61. Walker SP, Wachs TD, Gardner JM et al. (2007) Child development: risk factors for adverse outcomes in developing countries. Lancet 369, 145-157.

62. Huttenlocher J, Haight W, Bryk A et al. (1991) Early vocabulary growth: relation to language input and gender. Dev Psychol 27, 236-248.

63. Stolarova M, Brielmann AA, Wolf C et al. (2016) Early vocabulary in relation to gender, bilingualism, type, and duration of childcare. Adv Cogn Psychol 12, 130-144. 